\title{
Meiosis in Cicer L. Species: The Relationship between Chiasma Frequency and Genome Length
}

\author{
F. Ahmad ${ }^{1, *}$ and Q. Chen ${ }^{2}$ \\ ${ }^{1}$ Botany Department, Brandon University, Brandon, Manitoba R7A6A9, Canada \\ ${ }^{2}$ Agriculture \& Agri-Food Canada Research Station, Lethbridge, Alberta, Canada
}

Accepted February 24, 2000

\begin{abstract}
Summary Meiotic chromosome pairing configurations were studied in 24 accessions representing all of the 9 annual Cicer species. The diploid chromosome number was confirmed to be $2 n=16$ in all the studied species. Meiosis in Cicer species was characterized by a rather diffused prophase, but nonetheless it progressed normally. Precocious as well as late disjunction of the longest chromosome pair was occasionally observed giving rise to false univalents and anaphase bridge, respectively. Regular 8 bivalents were characteristically observed in all the species. Only one chromosome pair was found to be associated with the nucleous at pachynema and/or diakinesis stage in all the accessions and species, including $C$. reticulatum which has been reported to have 2 pairs of satellited chromosomes containing rRNA gene cluster. There was little variaiton in chiasma frequency per PMC among accessions within a species, but considerable variation among species. The mean number of rod bivalents per PMC ranged from 2.62 in C. cuneatum to 6.12 in C. echinospermum, while the number of ring bivalents per PMC ranged from 1.89 in C. echinospermum to 5.38 in C. cuneatum. Chiasma frequency per unit genome length was primarily a function of the diploid genome length and showed a negative relationship $\left(\hat{Y}=0.780-0.016 \mathrm{X}, \mathrm{r}^{2}=0.86\right)$. The role of proportion of repetitive DNA sequences, in the form of heterochromatin, present in the genome and its distribution among chromosomes of the various Cicer species genome have been speculated to explain this negative relationship.
\end{abstract}

The genus Cicer L., of tribe Circereae, is best known by the globally important cultivated species $C$. arietinum $\mathrm{L}$. Other than the cultivated species, it also comprises 42 related species of which 8 are annual, 33 perennial and one species of as yet unspecified life cycle (van der Maesen 1987). All the so far studied Cicer species have revealed a diploid chromosome number of $2 n=16$ (Ahmad 2000). The related wild species are an immense reservoir of useful genetic traits (Singh et al. 1998) and attempts are already in progress to exploit it for the genetic improvement of cultivated chickpea (Singh and Ocampo 1997). An understanding of the genetic and cytological makeup of the related wild species would be beneficial in their utilization in chickpea genetic improvement efforts.

A few incomplete and rather scattered studies have been conducted to determine the morphology and behavior of individual chromosomes in the cultivated chickpea and related Cicer species (Ladizinsky and Adler 1976a, b, Sharma and Gupta 1986, Ahmad and Hymowitz 1993). While all studies reported that the number of chiasmata per PMC differed between species, meiosis was normal in different species, with 8 bivalents at metaphase I. However, no effort have been made to characterize the relative proportion of the ring and rod types of bivalents. Additionally, in view of the fact that various Cicer species differ in their genome size (Ohri and Pal 1991, Ocampo et al. 1992, Tayyar et al. 1994, Galasso et al. 1996, Ahmad 2000) as well as chiasma frequency (Ladizinsky and Adler 1976a, b, Sharma and Gupta 1986), the recombination frequency-genome size relationship and its underelying cause in the genus Cicer is very poorly understood. In other plant

* Corresponding author, e-mail: ahmad@brandonu.ca 
species, a negative relationship between recombination and genome size has been previously suggested (Cavalier-Smith 1985) and later demonstrated (Rees and Durrant 1986).

In this study, we have specifically studied the meiotic process and characterized the bivalents and recombination frequency in all of the 9 annual Cicer species. Using the genome size data from our previous work (Ahmad 2000), we have also deduced a relationship between recombination frequency and genome size in Cicer and discuss that in light of our current understranding of the genus.

\section{Material and methods}

The experimental material consisted of 24 accessions of the genus Cicer, which included representatives of all the 9 annual species from different geographical parts of the world. These were: 5 accessions of C. arietinum (Mission, Spanish, ILC 482, ILC 135, Radhe), 4 accessions of C. reticulatum Lad. (ICCW 6, ICCW 8, ICCW 9, ICCW 9a), 2 accessions of $C$. echinospermum Dav. (ICCW 44, PI 489776), 2 accessions of $C$. pinnatifidum J. et S. (ICCW 37, ICCW 40), 3 accessions of C. judaicum Boiss. (ICCW 33, ICCW 34, ICCW 36), 3 accessions of C. bijugum Rech. (ICCW 7, ICCW 10, ICCW 42), 2 accessions of C. chorassanicum (Bge.) M. Pop (PI 458553, ICCW 26), 2 accessions of $C$. yamashitae Kit. (ICCW 1, ICCW 2), and 1 accession of C. cuneatum Rich. (ICCW 47). For convenience, these species are represented by their 3-letter abbreviation, viz. ARI, RET, ECH, PIN, JUD, BIJ, CHO, YAM and CUN, respectively, as used previously by Ahmad (1999).

Flower buds, of appropriate developmental stage, were collected from greenhouse grown plants and fixed at room temperature for $24 \mathrm{~h}$ in Carnoy's fixative (6 parts 95\% ethanol: 3 parts chloroform : 1 part glacial acetic acid, v/v) to which trace amounts of ferric chloride $\left(\mathrm{FeCl}_{3}\right)$ were added to enhance staining. After $24 \mathrm{~h}$ of fixation, buds were stored in $70 \%$ ethanol at about $4{ }^{\circ} \mathrm{C}$ until analyzed. For study of chromosome associations at metaphase I and behavior of chromosomes at other meiotic stages, individual anthers were stained and squashed in slightly warm $2 \%$ acetocarmine stain. All cytological observations were made on temporary slides. Photomicrographs were taken with a Zeiss research microscope fitted with a photographic attachment. Data was collected specifically for the number of rod (open) and ring (closed) bivalents within a pollen mother cell (PMC) of individual accessions of each annual Cicer species. Calculated chiasma frequency per unit length of the genome was then plotted against various Cicer species genome length reported by Ahmad (2000). The genome data used from Ahmad (2000) indicates, ARI, RET, ECH, PIN, JUD, BIJ, CHO, YAM and CUN to have a diploid genome length of and 35.2, 27.7, 41.3, 33, 31.5, 34.6, $30.9,30.2$, and $29.8 \mu \mathrm{m}$, respectively. A regression equation was developed based on these data.

\section{Results and discussion}

Meiosis in all 9 annual Cicer species was characterized by a rather diffused prophase, making pachytene analysis difficult but not impossible, as clearly shown by the recent report of Ahmad and Hymowitz (1993). It was at diakinesis that bivalents could be first seen, and they remained highly condensed at metaphase I, making interpretations difficult. It was not until the homologous centromeres started moving to opposite poles with the bivalents slightly stretched in line with the division axis, that any further interpretation of meiotic associations could be made. In all the accessions and species, only one chromosome pair was found to be associated with the nucleolus at pachyne$\mathrm{ma}$ and/or diakinesis statge. This is an interesting observation especially for RET in which two pairs of satellited chromosome have been reported (Ohri and Pal 1991, Ocampo et al. 1992, Tayyar et al. 1994, Galasso et al. 1996) and that the rRNA gene cluster have been mapped to 2 pairs of chromosome (Abbo et al. 1994, Galasso et al. 1996). Additionally, both of these rRNA gene sites 

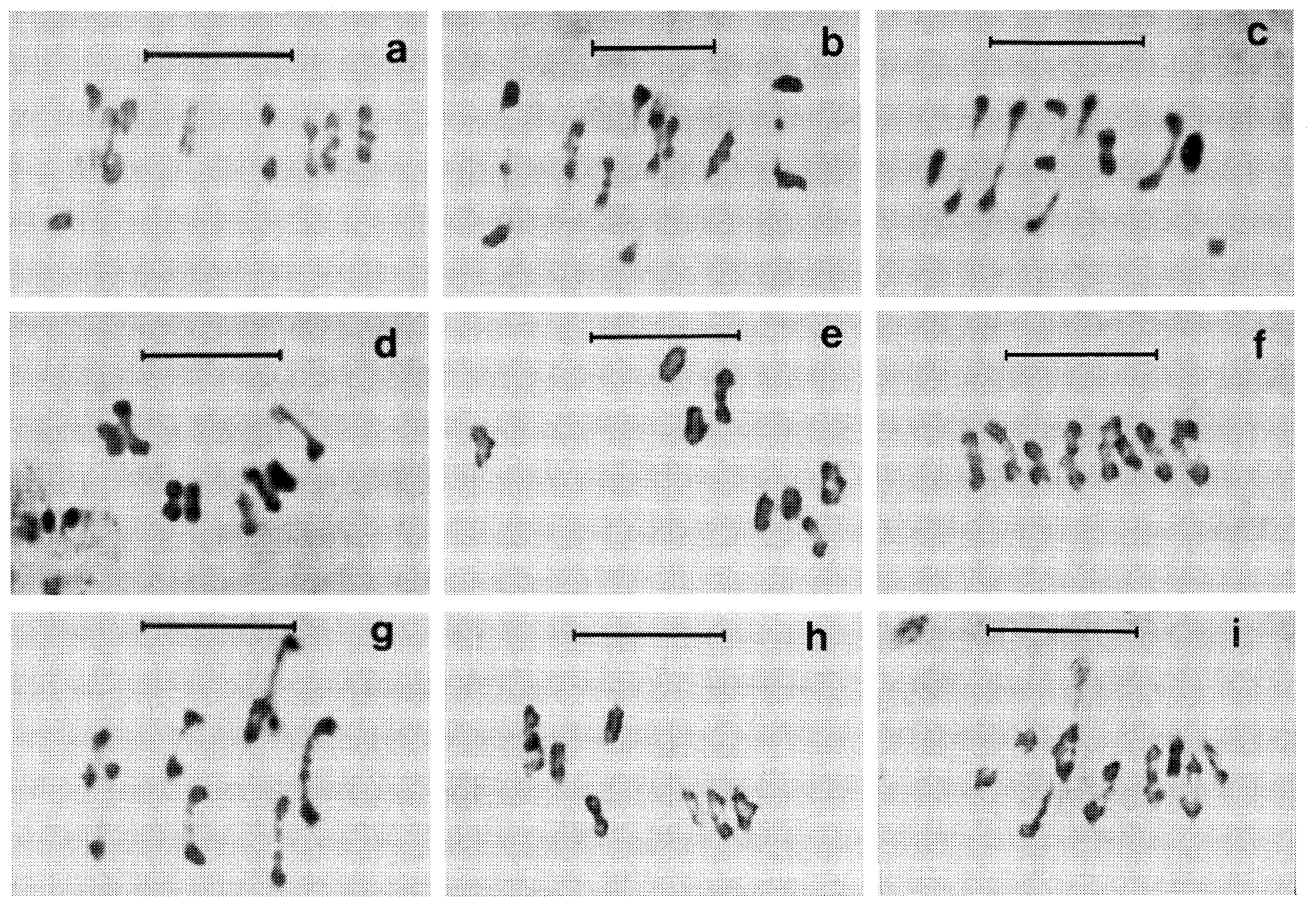

Fig. 1. Meiotic metaphase I configurations in the annual Cicer species. a) C. arietinum, b) C. reticulatum, c) C. echinospermum, d) C. pinnatifidum, e) C. judaicum, f) C. bijugum, g) C. chorassanicum, h) C. yamashitae, i) C. cuneatum. Bar represents $10 \mu \mathrm{m}$.

are transcriptionally active, albeit differentially, and are thus capable of forming nucleoli (Galasso et al. 1996). Our cytological observation in RET would, thus, indicate that perhaps the chromosome pair containing the lesser active of the 2 rRNA site is not capable of associating with the nucleolus at the pachynema/diakinesis stage, since not a single PMC showed this expected association. A similar situation has recently been reported in cultivated fenugreek, Trigonella foenum-graecum L. (Ahmad et al. 1999). Ocampo et al. (1992) reported that even PIN has 2 satellited chromosome pair, a result not corroborated by any other study, but again only a single chromosome pair associated with nucleolus in this species as well. Results clearly indicated that every single accession invariably showed 8 bivalents at metaphase I (Fig. 1, Table 1), also confirming their diploid chromosome number to be $2 \mathrm{n}=16$, as reported by other researchers (Sharma and Gupta 1986, Ohri and Pal 1991, Ocampo et al. 1992, Tayyar et al. 1994, Ahmad 2000) on the basis of mitotic chromosome studies.

There was little variation in chiasma frequency per PMC among accessions within a species, but considerable variation among species (Table 1). In general, there were more open (rod) bivalents than closed (ring) bivalents in the various Cicer species, with the exception of CUN in which case the reverse was true, while JUD and BIJ showed approximately equal frequency of open and close bivalents (Table 1). The mean number of rod bivalents per PMC ranged from 2.62 in CUN to 6.12 in $\mathrm{ECH}$, while the number of ring bivalents per PMC ranged from 1.89 in ECH to 5.38 in CUN (Table 1). Apart from these differences, no gross differences were observed at any of the various meiotic stages in the 9 Cicer species.

Due to the small size of Cicer chromosomes and their highly condensed state at meiosis, it was difficult to recognize most of the chromosomes by differences in length. However, when chromosomes within a complement differed significantly in length, it was possible to distinguish the longer chromosomes from the other shorter chromosomes. In such situations, as observed in ARI, RET 
Table 1. Meiotic associations and chiasma frequency in nine annual Cicer species

\begin{tabular}{|c|c|c|c|c|c|}
\hline \multirow{2}{*}{ Species } & \multirow{2}{*}{ Accession } & \multirow{2}{*}{ "PMC } & \multicolumn{2}{|c|}{ Number of bivalents } & \multirow{2}{*}{ Chiasmata/PMC } \\
\hline & & & Ring IIs & Rod IIs & \\
\hline \multirow[t]{5}{*}{ C. arietinum (ARI) } & Mission & 26 & $1.69(0-4)^{\dagger}$ & $6.31(4-8)^{\dagger}$ & $9.69 \pm 0.97^{\ddagger}$ \\
\hline & Spanish & 33 & $2.91(1-4)$ & $5.09(4-7)$ & $10.91 \pm 1.01$ \\
\hline & ILC 482 & 36 & $2.53(1-4)$ & $5.47(4-7)$ & $10.53 \pm 1.08$ \\
\hline & ILC 135 & 30 & $2.37(1-4)$ & $5.63(4-7)$ & $10.37 \pm 1.00$ \\
\hline & Radhe & 34 & $1.59(0-3)$ & $6.41(5-8)$ & $9.59 \pm 1.02$ \\
\hline Species Mean & & 159 & 2.22 & 5.78 & 10.22 \\
\hline \multirow[t]{4}{*}{ C. reticulatum (RET) } & ICCW 6 & 30 & $2.37(0-4)$ & $5.63(4-8)$ & $10.37 \pm 1.27$ \\
\hline & ICCW 8 & 31 & $1.90(0-4)$ & $6.10(4-8)$ & $9.90 \pm 1.16$ \\
\hline & ICCW 9 & 41 & $2.12(1-8)$ & $5.88(0-7)$ & $10.12 \pm 1.33$ \\
\hline & ICCW 9a & 30 & $2.23(0-4)$ & $5.77(4-8)$ & $10.23 \pm 1.26$ \\
\hline Species Mean & & 132 & 2.16 & 5.85 & 10.16 \\
\hline \multirow[t]{2}{*}{ C. echinospermum $(\mathrm{ECH})$} & ICCW 44 & 36 & $2.00(0-4)$ & $6.00(4-8)$ & $10.00 \pm 1.20$ \\
\hline & PI 489776 & 31 & $1.77(0-4)$ & $6.23(4-8)$ & $9.77 \pm 1.12$ \\
\hline Species Mean & & 67 & 1.89 & 6.12 & 9.89 \\
\hline \multirow[t]{2}{*}{ C. pinnatifidum (PIN) } & ICCW 37 & 31 & $2.65(0-6)$ & $5.35(2-8)$ & $10.58 \pm 1.69$ \\
\hline & ICCW 40 & 27 & $3.00(1-5)$ & $5.00(3-7)$ & $11.00 \pm 1.18$ \\
\hline Species Mean & & 58 & 2.83 & 5.18 & 10.79 \\
\hline \multirow[t]{3}{*}{ C. judaicum (JUD) } & ICCW 33 & 60 & $4.13(1-8)$ & $3.87(0-7)$ & $12.13 \pm 2.16$ \\
\hline & ICCW 34 & 31 & $4.32(1-8)$ & $3.68(0-7)$ & $12.32 \pm 1.74$ \\
\hline & ICCW 36 & 33 & $3.64(1-8)$ & $4.36(0-7)$ & $11.58 \pm 1.79$ \\
\hline Species Mean & & 124 & 4.03 & 3.97 & 12.01 \\
\hline \multirow[t]{3}{*}{ C. bijugum (BIJ) } & ICCW 7 & 69 & $4.28(2-8)$ & $3.72(0-6)$ & $12.28 \pm 1.29$ \\
\hline & ICCW 10 & 36 & $3.94(1-6)$ & $4.06(2-7)$ & $11.94 \pm 1.24$ \\
\hline & ICCW 42 & 30 & $3.57(1-6)$ & $4.43(2-7)$ & $11.57 \pm 1.33$ \\
\hline Species Mean & & 135 & 3.93 & 4.07 & 11.93 \\
\hline \multirow[t]{2}{*}{ C. chorassanicum $(\mathrm{CHO})$} & PI 458553 & 45 & $3.35(0-7)$ & $4.65(1-8)$ & $11.35 \pm 1.70$ \\
\hline & ICCW 26 & 29 & $4.21(2-6)$ & $3.79(2-6)$ & $12.21 \pm 1.05$ \\
\hline Species Mean & & 74 & 3.78 & 4.22 & 11.78 \\
\hline \multirow[t]{2}{*}{ C. yamashitae (YAM) } & ICCW 1 & 25 & $2.88(1-5)$ & $5.12(3-7)$ & $10.88 \pm 1.17$ \\
\hline & ICCW 2 & 30 & $3.60(2-6)$ & $4.40(2-6)$ & $11.60 \pm 1.00$ \\
\hline Species Mean & & 55 & 3.24 & 4.76 & 11.24 \\
\hline C. cuneatum (CUN) & ICCW 47 & 41 & $5.38(4-8)$ & $2.62(0-4)$ & $13.38 \pm 1.28$ \\
\hline
\end{tabular}

${ }^{\dagger}$ Range in parentheses. ${ }^{\ddagger}$ Mean \pm standard deviation

and $\mathrm{ECH}, 2$ or 3 of the comparatively longer chromosomes consistently formed rod bivalents with only one chiasma each, while the shorter chromosomes often formed ring bivalents with 2 chiasmata each (Fig. 1). This was also true in the remaining species which were characterized by chromosomes of intermediate length and rather less asymmetrical karyotypes. However, this distinction was not as clear as for the above mentioned 3 species due to the small coefficient of interchromosomal variation (Ahmad 2000). In other words, in the genus Cicer, the shorter chromosomes frequently form ring bivalents, whereas the longer chromosomes frequently form rod bivalents. Similar observations were made by Sharma and Gupta (1986). For the most part, meiosis progressed normally in all 9 annual Cicer species. However, precocious disjunction of 1 or 2 bivalents was observed in some PMC's of ARI, RET and ECH. In the same 3 species, the longest bivalent would occasionally separate late in the anaphase I and anaphase II, thus giving the appearance of a chromatin bridge. No univalents were observed in any of the 9 annual Cicer species.

Various researchers have reported on the genome length in various species of the genus Cicer (Kabir and Singh 1990, Ocampo et al. 1992, Ahmad and Hymowitz 1993, Tayyar et al. 1994), but data on chiasma frequency in the same precise accessions remain unknown. Since nuclear DNA content and genome length could vary among accessions of the same species (Ohri and Pal 1991), it 
is critical to have data on both parameters from the same accessions when comparing genome length with chiasma frequency. In this aspect, our data on Cicer species karyotype (Ahmad 2000) and chiasma frequency (this study) meets the criteria and have been used to deduce a relationship between recombination frequency (or chiasma frequency) per PMC and genome length. We have previously shown that, in the annual species of genus Cicer, the longest and shortest genome length are shown by ECH and CUN, respectively (Ahmad 2000). Incidentally, these 2 species also have the lowest and highest chiasma frequency (Table 1, Fig. 2). Other species accessions show values intermediate to these two and lead us to conclude that, among the studied species of the genus Cicer, chiasma frequency per unit genome length is primarily a function of the diploid genome length $\left(r^{2}=0.86\right.$, Fig. 2). The relationship between these two parameters is negative, as revealed by the regression equation $(\hat{\mathrm{Y}}=0.87-0.016 \mathrm{X})$. Reported data from certain other plant species, such as Lathyrus, Lolium and Petunia, also corroborate our conclusion of a negative relationship (Rees and Durrant 1986). Cavalier-Smith (1985) have also prevciously suggested a negative relationship between recombination and genome size, as part of the nucleotype effect of genome size.

What could then be the explanation of such a negative relationship between recombination frequency and genome size? Perhaps, the amount of heterochromatin (largely repetitive DNA) present in the genome (Rees and Durrant 1986) and its distribution among chromosomes of the genome could be one of the explanations to this observation. Changes in amount of DNA are often accompanied by changes in DNA composition, e.g., the proportion of repetitive DNA generally increased with an increase in the amount of DNA in Lathyrus (Narayan 1982). In the genus Cicer, however, it has been observed that increase in the proportion of repetitive DNA does not correspond with the increased DNA content in evolutionary lineage (Ohri and Pal 1991), and there have been interchromosomal shuffling of repetitive DNA sequences within the genome (Tayyar et al. 1994, Galasso et al. 1996). In at least some of the repetitive segments, such as those located in heterochromatin, chiasmata do not form. Equally important, perhaps, these highly repetitive sequences may suppress recombination in their vicinity (John and King 1980). Thus, it may be quite possible that higher heterochromatin content containing chromosomes may show lesser recombination and vice versa (reflected in rod and ring bivalents, respectively). This line of reasoning is at least supportred by the 2 longest chromosomes $(\# 1,2)$ of ARI which is largely heterochromatic (Ahmad and Hymowitz 1993, Tayyar et al. 1994, Venora et al. 1995) and consistently shows less recombination as expressed in the form of rod shaped bivalents, whereas the other chromosomes contain proportionally less heterochromatin and often manifest themselves as ring bivalents. While information on within genome heterochromatin content is available for the annual Cicer species (Galasso and Pignone 1992, Tayyar et al. 1994, Venora et al. 1995, Galasso et al. 1996), detailed information about its relative distribution among the 8 pairs of chromosomes of any given species remains largely unknown. Such information is much needed in order to lend further support or refute this negative re- 
lationship between recombination and genome size, as exemplified by the genus Cicer and other plant species.

\section{Acknowledgments}

The senior author sincerely acknowledges Brandon University (Brandon, MB, Canada) for providing the facility and the scientific environment for carrying out this research.

\section{References}

Abbo, S., Miller, T. E., Reader, S. M. Dunford, R. P. and King, I. P. 1994. Detection of ribosomal DNA sites in lentil and chickpea by fluorescent in situ hybridization. Genome 37: 713-716.

Ahmad, F. 1999. Random amplified polymorphic DNA (RAPD) analysis reveals genetic relationships among the annual Cicer species. Theor. Appl. Genet. 98: 657-663.

$\longrightarrow 2000$. A comparative study of chromosome morphology among the nine annual species of Cicer L. Cytobios 101: 37-53.

$\longrightarrow$ Acharya, S. N., Mir, Z. and Mir, P. S. 1999. Localization and activity of rRNA genes on fenugreek (Trigonella foenumgraecum L.) chromosomes by fluorescent in situ hybridization and silver staining. Theor. Appl. Genet. 98: $179-185$.

$\longrightarrow$ and Hymowitz, T. 1993. The fine structure of chickpea (Cicer arietinum L.) chromosomes as revealed by pachytene analysis. Theor. Appl. Genet. 86: 637-641.

Cavalier-Smith, T. 1985. Eukaryote Gene Numbers, Non Coding DNA and Genome Size. In: Cavalier-Smith, T. (ed.). The Evolution of Genome Size. Wiley Pub., New York. pp. 69-103.

Galasso, I, Frediani, M., Maggiani, M., Cremonini, R. and Pignone, D. 1996. Chromatin characterization by banding techniques, in situ hybridization, and nuclear DNA content in Cicer L. (Leguminosae). Genome 39: 258-265.

$\smile$ and Pignone, D. 1992. Characterization of chickpea chromosomes by banding techniques. Genet. Res. Crop Evol. 39: $115-119$.

John, B. and King, M. 1980. Heterochromatin variation in Cryptobothrus chrysophorus. 3. Synthetic hybrids. Chromosoma 78: $165-186$.

Kabir, G. and Singh, R. M.. 1990. Karyotype analysis of six species of Cicer L. Bangladesh J. Bot. 19: 175-181.

Ladizinsky, G. and Adler, A. 1976a. Genetic relationships among the annual species of Cicer L. Theor. Appl. Genet. 48: 197-203.

$\smile$, $1976 \mathrm{~b}$. The origin of chickpea, Cicer arietinum L. Euphytica 25: 211-217.

Narayan, R. K. J. 1982. Discontinuous DNA variation in the evolution of plant species: the genus Lathyrus. Evolution 36: $877-891$

Ocampo, B., Venora, G., Errico, A., Singh, K. B. and Saccardo, F. 1992. Karyotype analysis in the genus Cicer. J. Genet. Breed, 46: 229-240.

Ohri, D. and Pal, M. 1991. The origin of chickpea (Cicer arietinum L.): karyotype and nuclear DNA content. Heredity 66: 367-372.

Rees, H. and Durrant, A. 1986. Recombination and genome size. Theor. Appl. Genet. 73: 72-76.

Sharma, P. C. and Gupta, P. K. 1986. Cytogenetics of Legume Genera Cicer L. and Lens L. In: Gupta, P. K. and Bahl, J. R. (eds.). Genetics and Crop Improvement. Rastogi and Company, Meerut, India. pp. 321-340.

Singh, K. B. and Ocampo, B. 1997. Exploitation of wild Cicer species for yield improvement in chickpea. Theor. Appl. Genet. 95: 418-423.

$\smile$, and Robertson, L. D. 1998. Diversity for abiotic and biotic stress resistance in the wild annual Cicer species. Genet. Res. Crop. Evol. 45: 9-17.

Tayyar, R. I., Lukaszewski, A. J. and Waines, J. G. 1994. Chromosome banding patterns in the annual species of Cicer. Genome 37: 656-663.

van der Maesen, L. J. G. 1987. Origin, History and Taxonomy of Chickpea. In: Saxena, M. C. and Singh, K. B. (eds.). The Chickpea. CAB Int. Publ., UK. pp. 11-34.

Venora, G., Galasso, I. and Pignone, D. 1995. Quantitative heterochromatin determination by means of image analysis. J. Genet. Breed. 49: 187-190. 